\title{
Investigations on the thermal release of iodine from liquid eutectic lead-bismuth alloy
}

\author{
By J. Neuhausen* and B. Eichler \\ Laboratory for Radio- and Environmental Chemistry, Paul Scherrer Institute, 5232 Villigen PSI, Switzerland
}

(Received October 24, 2005; accepted in revised form January 17, 2006)

Release / Pb-Bi-Eutecticum / LBE / Evaporation / Iodine

Summary. The release of iodine from liquid eutectic leadbismuth alloy (LBE) under a flowing $\mathrm{Ar} / 7 \% \mathrm{H}_{2}$ atmosphere has been studied in a temperature range from 428 to $1223 \mathrm{~K}$ using $\gamma$-ray spectroscopy. During short-term experiments, significant amounts of iodine evaporate from liquid LBE at temperatures higher than $800 \mathrm{~K}$. Long-term experiments reveal that the release of iodine at temperatures of relevance to technical applications, such as liquid metal spallation targets or Accelerator Driven Systems (ADS), is below our detection limits for periods up to 7 days. The release rate is determined by the desorption/evaporation process rather than by diffusion within the liquid alloy.

\section{Introduction}

A eutectic mixture of lead and bismuth (LBE) is considered to be useful as target material in liquid metal spallation targets [1] as well as in Accelerator Driven Systems (ADS) for the transmutation of long-lived nuclear waste [2]. In those systems iodine will be formed by nuclear reactions. An assessment of accident scenarios shows that the release of iodine from those systems in an accidental case may pose a major risk to the environment [3]. However, the chemical behaviour of iodine in liquid LBE - and hence its release properties - are not yet well understood. Investigations on the release of iodine from liquid metals are scarce. The distribution of iodine between liquid metal and gas phase in a liquid bismuth loop has been determined under helium atmosphere at $773 \mathrm{~K}$ [4]. The release of iodine from liquid lanthanum and uranium in ISOL targets has been studied [5-8]. Iodine release from liquid sodium was investigated in connection with LMFBR technology $[9,10]$. However, no experimental investigations on the release of iodine from LBE were performed so far. The thermochemical relations of iodine in a liquid LBE spallation target have been studied by us [11]. From the results of this evaluation the release of large fractions of iodine from a liquid LBE spallation target under normal operating conditions, i.e. under an inert gas atmosphere enriched with hydrogen formed by spallation, is unlikely. To confirm these results experimentally, we

\footnotetext{
*Author for correspondence (E-mail: joerg.neuhausen@psi.ch).
}

studied the thermal release behaviour of iodine from liquid LBE under an $\mathrm{Ar} / 7 \% \mathrm{H}_{2}$ atmosphere.

\section{Experimental}

LBE samples (44.8 wt. \% Pb, 55.2 wt. \% Bi) were prepared by melting appropriate amounts of $\mathrm{Pb}$ foil (Alfa Aesar, 99.9999\%) and Bi pieces (Alfa Aesar, 99.9999\%) at $773 \mathrm{~K}$ for $1 \mathrm{~h}$ under an $\mathrm{Ar} / 7 \% \mathrm{H}_{2}$-atmosphere. Doping with natural uranium was achieved by partially solving a piece of U-foil in the liquid alloy. The insoluble uranium was afterwards separated from the alloy. The samples were then activated by neutron irradiation in SINQ, where iodine nuclides are formed from uranium by fission reactions. The samples were allowed to decay for 7-9 days and subsequently cut in pieces to achieve activities suitable for $\gamma$-ray spectroscopy. Typical sample masses were $0.3-1.1 \mathrm{~g}$ for short-term and $2.3 \mathrm{~g}$ for long-term experiments. For an approximate determination of the uranium concentration in the sample, standards containing a known amount of uranium were prepared and irradiated in SINQ. $\gamma$-ray spectra of those standards were recorded under the same conditions (measuring geometry, decay time) as for the samples used for release experiments. The uranium content was then determined from the peak area ratio of the $334.3 \mathrm{keV} \gamma$-ray signal of ${ }^{239} \mathrm{~Np}$, which is formed by neutron capture of ${ }^{238} \mathrm{U}$ and subsequent $\beta^{-}$-decay of ${ }^{239} \mathrm{U}$. Self-absorption effects within the LBE samples were roughly estimated based on sample thickness and mass attenuation coefficients listed in [12]. Typical mole fractions of $U$ in the LBE samples are about $10^{-4}$ to $10^{-3}$.

The number of nuclei and concentrations of ${ }^{131} \mathrm{I}$ and ${ }^{132} \mathrm{I}$ in the samples were determined from the peak areas of the characteristic $\gamma$-rays of the respective nuclide ${ }^{131} \mathrm{I}$ : $364.49 \mathrm{keV},{ }^{132} \mathrm{I}$ : 667.72 and $772.60 \mathrm{keV}$ ) taking into account the detector efficiency and $\gamma$-ray branching [13]. Selfabsorption effects were roughly estimated based on sample thickness and mass attenuation coefficients listed in [12].

Typical numbers of nuclei at the start of release experiments were in the range of $10^{8}$ to $10^{9}$ for ${ }^{131} \mathrm{I}$ and $10^{7}$ to $10^{8}$ for ${ }^{132} \mathrm{I}$. The corresponding mole fractions were in the range of $10^{-13}$ to $10^{-12}$ for ${ }^{131} \mathrm{I}$ and $10^{-14}$ to $10^{-13}$ for ${ }^{132} \mathrm{I}$.

Evaporation experiments (one experiment for each temperature setting) were performed using the experimental setup illustrated in Fig. 1. Before the experiment, the samples 


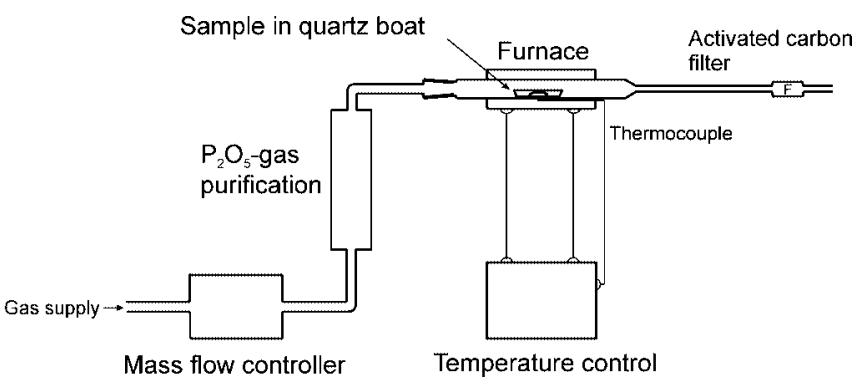

Fig. 1. Schematic drawing of the experimental arrangement.

were scratched to remove the surface oxide layer. The samples were then placed on a quartz tissue within a quartz boat, which was placed in a quartz tube. This tube was flushed with an $\mathrm{Ar} / 7 \% \mathrm{H}_{2}$ mixture (purity: $\mathrm{H}_{2}>99.993 \%$, Ar $>99.998 \%$ ), which was previously run through a column containing a Pd-contact to facilitate the establishment of $\mathrm{O}_{2} / \mathrm{H}_{2} / \mathrm{H}_{2} \mathrm{O}$ equilibrium and Sicapent (with indicator, Merck, Germany) for removing moisture. A partial pressure of water of $3.7 \pm 1.7 \mathrm{hPa}$ was determined using a $\mathrm{Zr} / \mathrm{Y}_{2} \mathrm{O}_{3}$ solid electrolyte cell. All experiments were performed using a continuous gas flow of $60 \mathrm{ml} / \mathrm{min}$ adjusted by a mass flow controller. The apparatus was flushed for approximately $20 \mathrm{~min}$ after the insertion of the sample to remove air contamination. The tube was resistance-heated to the desired temperatures, which were measured and controlled using thermocouples and a thyristor controller. Two charcoal filters were placed at the end of the tube to prevent volatile radioactive species from reaching the exhaust. $\gamma$-ray spectroscopic measurements were performed using an HPGedetector.

Short-term experiments: A $\gamma$-ray spectrum of the sample was recorded before each heating experiment. The sample was then placed into the evaporation apparatus, which was flushed with the appropriate gas mixture. After approximately $20 \mathrm{~min}$, the apparatus was heated to the desired temperature within $10 \mathrm{~min}$ and kept at that temperature for 50 min. Subsequently, the sample was cooled to room temperature within $10 \mathrm{~min}$ using a fan. A $\gamma$-ray spectrum was recorded after the experiment. The fractional release of iodine was calculated comparing the integrated peak areas of the characteristic $\gamma$-rays of ${ }^{131} \mathrm{I}$ and ${ }^{132} \mathrm{I}$ before and after heating. The error bars given in the figure correspond to the standard errors of the mean values obtained by averaging the fractional release calculated for each characteristic $\gamma$-ray of the two nuclides. For ${ }^{132} \mathrm{I}$ corrections for decay and formation from its precursor ${ }^{132} \mathrm{Te}$ during heating, cooling and measurement have been applied. ${ }^{206} \mathrm{Bi}\left(t_{1 / 2}=6.24 \mathrm{~d}\right.$ [13]), which is formed by $(n, x n)$ reactions during neutron irradiation, has been used as an internal standard to correct for geometry and self-absorption changes that may occur between the measurements before and after heating due to the melting process. For this purpose, the peak area ratios before and after heating for the characteristic $\gamma$-rays of the internal standard lying energetically close to the characteristic $\gamma$-rays of the investigated iodine nuclides were determined and the iodine signals were corrected accordingly. No measurable evaporation of $\mathrm{Bi}$ was detected at temperatures below $1223 \mathrm{~K}$. For the sample heated at $1223 \mathrm{~K}$, a small loss of $\mathrm{Bi}$ was observed giving rise to a small underestimation (maximum 2\%) of the fractional iodine release.

Long-term experiments: In principle, the same experimental set-up was used as in the short-term experiments. However, the $\gamma$-ray detector was cooled by a water circuit and placed directly under the reaction vessel. $\gamma$-ray spectra were taken repeatedly for periods up to 7 days. For the evaluation of these measurements only the ${ }^{131} \mathrm{I} \gamma$-ray peak at $364.49 \mathrm{keV}$ was used because of the short half-life of ${ }^{132} \mathrm{I}$ $(2.3 \mathrm{~h})$ and its precursor ${ }^{132} \mathrm{Te}(76.3 \mathrm{~h})$. A decay correction was applied to the integrated peak areas of the $\gamma$-ray signals of both volatile species and internal standard. The $\gamma$-ray signal at $343.51 \mathrm{keV}$ of ${ }^{206} \mathrm{Bi}$ [13] was used for geometry corrections. The error bars indicated in Fig. 3 were determined from the statistical $1 \sigma$ errors of iodine and standard signals before and after heating.

\section{Results and discussion}

The results of the short-term evaporation experiments are shown in Fig. 2. At temperatures below $800 \mathrm{~K}$ the release of iodine from LBE in an $\mathrm{Ar} / 7 \% \mathrm{H}_{2}$ atmosphere is below the experimental error indicated by error bars. Measurable amounts of iodine are released only at higher temperatures. $50 \%$ of the total amount of iodine is released within $1 \mathrm{~h}$ at about $900 \mathrm{~K}$. Hence, in agreement with our thermochemical evaluations [11] the release of iodine due to evaporation expected within a liquid metal spallation target (operating temperatures $473-723 \mathrm{~K}$ ) is small.

At temperatures higher than $1000 \mathrm{~K}$ the release curve runs into a plateau. The maximum fractional release observed under the present experimental conditions amounts to about $85 \%$. The remaining iodine may be bound within a thin oxide layer formed by the reaction of the dissolved uranium with the quartz tissue carrying the sample. Figure 3 shows the $\gamma$-ray spectra before and after the release experiment of an LBE sample heated at $1223 \mathrm{~K}$ for one hour. This sample was etched for approx. $15 \mathrm{~s}$ in $5 \mathrm{ml}$ of concentrated $\mathrm{HNO}_{3}$ after the release experiment to remove the surface layer of the sample. Additional $\gamma$-ray spectra of the LBE

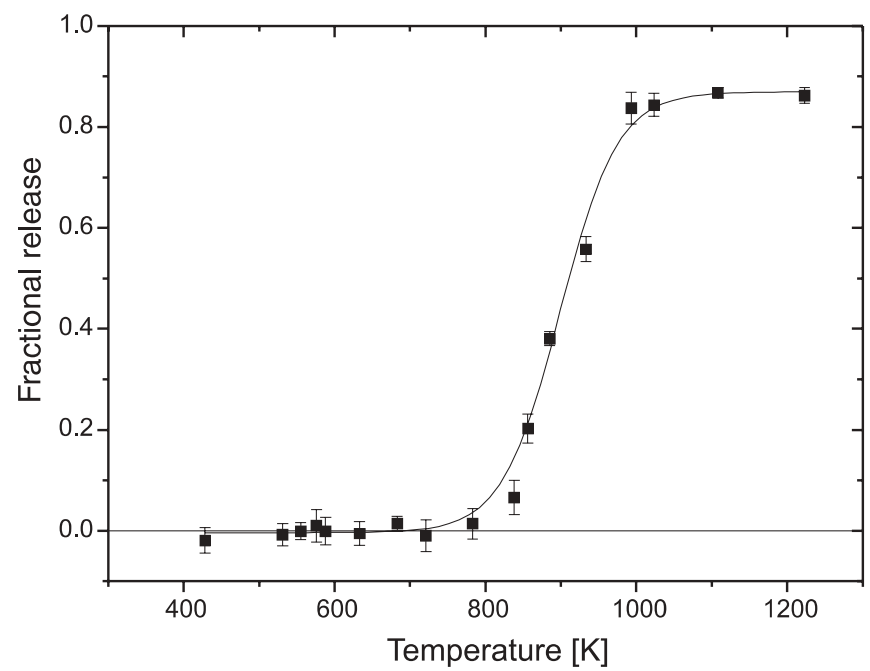

Fig. 2. Fractional release of iodine from LBE (1 $\mathrm{h}$ experiments) in $\mathrm{Ar} / 7 \% \mathrm{H}_{2}$ atmosphere as a function of temperature. 


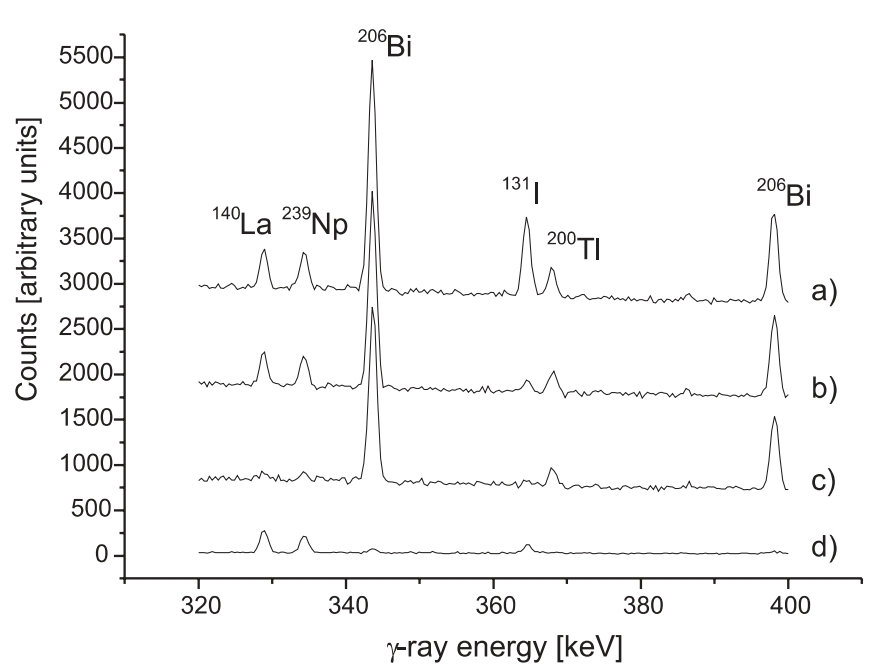

Fig. 3. Comparison of $\gamma$-ray spectra taken from a neutron irradiated LBE sample containing uranium: (a) spectrum taken before release experiment; (b) spectrum taken after release experiment (heating at $1223 \mathrm{~K}$ in an $\mathrm{Ar} / 7 \% \mathrm{H}_{2}$ flow of $60 \mathrm{ml} / \mathrm{min}$ for $1 \mathrm{~h}$ ); (c) spectrum after removal of the surface layer by etching; (d) spectrum of the solution obtained by etching. Signals of specific nuclides are indicated.

sample as well as of the $\mathrm{HNO}_{3}$ solution obtained by etching were recorded after etching. The spectra show signals of the characteristic $\gamma$-rays of ${ }^{206} \mathrm{Bi}$ and ${ }^{200} \mathrm{Tl}$ formed from LBE by $(n, x n)$ reactions (and subsequent $\beta^{+} / \varepsilon$ decay for ${ }^{200} \mathrm{Tl}$ ) as well as ${ }^{131} \mathrm{I}$ and ${ }^{140} \mathrm{La}$ formed by fission of uranium. ${ }^{239} \mathrm{~Np}$ is formed by neutron activation of ${ }^{238} \mathrm{U}$ and subsequent $\beta^{-}$-decay of ${ }^{239} \mathrm{U}$. A comparison of the spectra taken before and after heating shows that about $85 \%$ of ${ }^{131} \mathrm{I}$ is evaporated from the sample (see also Fig. 2). As indicated by the spectrum of the LBE sample after etching and the spectrum of the solution obtained by etching, the remaining iodine, together with ${ }^{140} \mathrm{La}$ and ${ }^{239} \mathrm{~Np}$, is almost completely removed from the LBE sample by etching off the surface. On the other hand, thallium is not enriched within the surface layer. The spectrum of the solution shows that only a very small amount of bismuth is dissolved. This supports the assumption that a uranium oxide layer resulting from the reaction of uranium with quartz is present. Within this oxide layer lanthanum and neptunium cations could substitute for uranium in the cation sublattice, while part of the iodine could be built into the oxygen sublattice in the form of iodide ions. In this chemical state iodine will be bound much tighter than in the liquid LBE matrix. Therefore, this fraction of iodine is not released in the temperature range investigated. Similar effects have to be expected in a liquid metal spallation target. Here, oxides that are not reduced by the spallation hydrogen can be formed by the reaction of electropositive spallation products with either the oxide layers of the construction materials or with the oxygen dissolved in the LBE target material. Those oxides can accumulate on the LBE surface. If iodine is bound within this oxide layer, its release from the target will be retarded.

Figure 4 deals with long-term experiments and shows the fractional release of iodine from LBE measured in an $\mathrm{Ar} / 7 \% \mathrm{H}_{2}$ atmosphere at different temperatures as a function of time for periods up to 7 days. At 722 and $771 \mathrm{~K}$, i.e. temperatures considerably above the operation temperatures considered for liquid LBE spallation targets such as

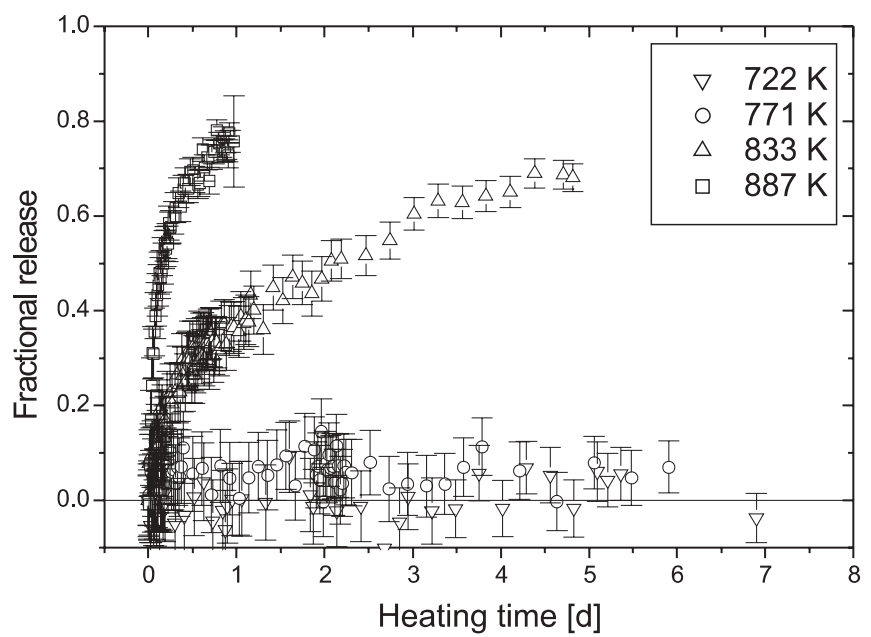

Fig. 4. Comparison of the long-term iodine release from LBE in an $\mathrm{Ar} / 7 \% \mathrm{H}_{2}$ atmosphere at different temperatures as a function of heating time.

MEGAPIE, no release is observed within the limits of the experimental errors. Fast release is observed at 833 and $887 \mathrm{~K}$, where within 1 day about 45 and $75 \%$ of the iodine present in the sample is given out, respectively.

From a physicochemical point of view thermal release can be regarded as an activated process involving different steps. For the simplest case of monoatomic species, diffusion of the volatile species to the surface and subsequent desorption and evaporation has to be taken into account. If a solid oxide layer is formed on the surface of LBE, the diffusion of volatile species will be additionally retarded. The extent of this effect depends on the formation kinetics of the oxide layer.

In case of release of iodine in form of specific molecules, e.g. HI, the formation reaction and the desorption/evaporation of the molecular species has to be taken into account. This qualitative assessment shows that the release of iodine from LBE is a complex process. A detailed study of the reaction mechanism is beyond the scope of this work. Nevertheless, from an estimation of the activation energy of the release process it may be possible to identify the step that determines the rate of evaporation. The description of the temperature dependency of iodine release using an Arrhenius-type relation results in an activation energy comparable to the bond energy given for gaseous $\mathrm{PbI}$ molecules $(192 \pm 40 \mathrm{~kJ} / \mathrm{mol})$ [14]. No data are available for the diffusion of iodine in either liquid lead or bismuth. However, typical values for the activation energies of diffusion in liquid metals are around 10-50 kJ/mol [15]. Hence, we conclude that the iodine release rate from LBE is probably not controlled by diffusion within the liquid alloy, but by a process which involves breaking of chemical bonds.

With respect to technical applications of liquid LBE such as spallation targets and ADS the following conclusions can be drawn:

Based on our results the release of large amounts of iodine from the liquid metal is not expected during the operation of liquid LBE spallation targets and ADS, confirming the results of thermochemical evaluations. Furthermore, in a liquid metal target spallation products could react with the oxide layers of construction mate- 
rials and the oxygen dissolved in the target material to form oxides that are not reducible by hydrogen. If these oxides accumulate at the LBE surface, iodine could be bound in the oxide layer in form of oxyiodides. To elucidate these influences, larger scale experiments with variation of sample size, concentration of volatiles, gas flow, temperature and flow conditions as well as with addition of representative elements for spallation products are planned.

Acknowledgment. This work was supported by the EU integrated project EUROTRANS under the contract $\mathrm{N}^{\circ}$ FI6W-CT-2004-516529 and the EU-RTD project TARGISOL (HPRI-CT-2001-50033). We thank Mr. H.-U. Aebersold for support at the neutron activation facility.

\section{References}

1. Salvatores, M., Bauer, G. S., Heusener, G.: The MEGAPIE Initiative, PSI-Report Nr. 00-05, Paul Scherrer Institut, Villigen, Switzerland (2000).

2. Gromov, B. F., Belomitlev, Yu. S., Efimov, E. I., Leonchuk, M. P., Martinov, P. N. Orlov, Yu. I., Pankratov, D. V., Pashkin, Yu. G., Toshinsky, G. I., Chenukov, V. V., Shmatko, B. A., Stepankov, V. S.: Use of lead-bismuth coolant in nuclear reactors and acceleratordriven systems. Nucl. Eng. Design 173, 207 (1997).

3. Fuchs, A., Jahn, S. G., Janett, A.: Störfallbetrachtungen für den MEGAPIE-Betrieb der SINQ und die daraus durch Radioaktivitätsabgabe resultierenden Personen-Dosen in der Umgebung des
PSI. TM-96-02-08, Paul Scherrer Institut, Villigen, Switzerland (2002).

4. Raseman, C. J., Susskind, H., Waide, C. H.: Pilot plant generation of fission products in uranium-bismuth reactor fuel. Chem. Eng. Prog. 53, 86 (1957).

5. Köster, U., for the ISOLDE Collaboration: ISOLDE target and ion source chemistry. Radiochim. Acta 89, 749 (2001).

6. Ravn, H. L., Sundell, S., Westgaard, L.: Target techniques for the ISOLDE on-line separator. Nucl. Instrum. Methods 123, 131 (1975).

7. Roussière, B. et al.: Release properties of $\mathrm{UC}_{x}$ and molten $\mathrm{U}$ targets. Nucl. Instrum. Methods B 194, 151 (2002).

8. Kandri-Rody, S. et al.: Exotic nuclei produced by fast neutrons in a liquid uranium target. Nucl. Instrum. Methods B 160, 1 (2000).

9. Feuerstein, H., Hooper, A. J., Johnson, F. A.: Mechanism of release of radioactive products into liquid-metal coolants, their transport within the circuits and removal from LMFBRS. At. Energy Rev. 17, 697 (1979).

10. Sauter, H., Schütz, W.: Aerosol- und Aktivitätsfreisetzung aus kontaminierten Natriumlachen in Inertgasatmosphäre. Report KFK-3504, Kernforschungszentrum Karlsruhe GmbH., Germany (1983).

11. Eichler, B., Neuhausen, J.: Analyse der thermochemischen Beziehungen des Iods in einem Blei-Wismut-Spallationstarget. TM-1803-01, Paul Scherrer Institut, Villigen, Switzerland (2003).

12. http://physics.nist.gov/PhysRefData/XrayMassCoef/tab3.html.

13. http://nucleardata.nuclear.lu.se/nucleardata/toi/.

14. Gurvic, L. V.: Energija razriva khimiceskikh Svjazei. Izd. Nauka, Moskva (1974) in Russian.

15. Landolt-Börnstein: Zahlenwerte und Funktionen aus Physik, Chemie, Astronomie, Geophysik und Technik. 6. Auflage, II. Band, 5. Teil B, Springer, Berlin (1968). 